\title{
The Influence of Entrained Air Amount of High-Performance Polycarboxylate Superplasticizer on the Performance of Concrete
}

\author{
Xigang Sun ${ }^{1, a}$,Guisheng Cai ${ }^{1, b}$, Liangqing Ma ${ }^{1, c}$ Tongwei LU ${ }^{1 \mathrm{~d}}$ \\ ${ }^{1}$ Shandong Provincial Academy of Building Research,Jinan 250031, China

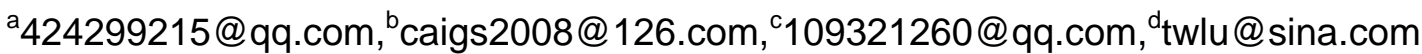

\begin{abstract}
Keywords:High-performance polycarboxylate superplasticizer, air content, pore srtucture Abstract: Air content in the concrete has an important effect on the performance. The relation of high-performance polycarboxylate superplasticizer with the air content of different grade concrete and the influence of air content in the concrete on the performance were studied. The relation of air content with the size and distribution of air bubbles was analyzed by porosity analyzer. The results show that the tiny bubbles are of great significance to improve the durability of concrete.
\end{abstract}

\section{Introduction}

The rapid development of high-speed railway and bridge construction promote the research and application of high-performance polycarboxylate superplasticizer. Polycarboxylate superplasticizer is thought a very effective additive to ensure the workability and durability of the infrastructure concrete, especially in the harsh environment.

Air content of concrete has an important effect on the workability, strength and durability and is strictly limited for the air content under the different environmental conditions in Chinese specifications. The design requirements, however, are difficultly met in the construction, let alone through adjusting the additive parameters. The effects of high-performance polycarboxylate superplasticizer on air content of concrete were studied though compressive strength, freezing-thaw resistance, distribution of air bubbles in this paper.

\section{Experiments}

\section{Raw materials}

Cement: PO42.5, made in Shanshui cement company.

Fly ash: I glass, made in Dezhou huaneng power plant.

Slag: S95, made in Shandong luxing company.

River Sand: median sand, 2.8 of fineness modulus.

Gravel stone: $5-31.5 \mathrm{~mm}, 38 \%$ of the smallest porosity.

Superplasticizer: polycarboxylate, NC-J, made by Shandong Institute of Architectural Science.

Air entrained agent: NC-Q, made by Shandong Institute of Architectural Science.

\section{Mixing Proportions}

Mixing proportions were shown in table 1 and the slumps were controlled in the range of $180-220 \mathrm{~mm}$ through adjusting the amount of superplasticizer.

Table1 Mixing proportion

\begin{tabular}{ccccccccc}
\hline & Water & cement & Fly ash & Slag & Sand & Stone & NC-J & NC-Q \\
No. & & & & & & & & \\
& $\left(\mathrm{Kg} / \mathrm{m}^{3}\right)$ & $\left(\mathrm{Kg} / \mathrm{m}^{3}\right)$ & $\left(\mathrm{Kg} / \mathrm{m}^{3}\right)$ & $\left(\mathrm{Kg} / \mathrm{m}^{3}\right)$ & $\left(\mathrm{Kg} / \mathrm{m}^{3}\right)$ & $\left(\mathrm{Kg} / \mathrm{m}^{3}\right)$ & $\left(\mathrm{Kg} / \mathrm{m}^{3}\right)$ & $\left(\mathrm{Kg} / \mathrm{m}^{3}\right)$ \\
1 & 151 & 252 & 72 & 36 & 766 & 1103 & 3.24 & \\
2 & 151 & 264 & 76 & 38 & 740 & 1110 & 3.78 & \\
3 & 151 & 278 & 80 & 40 & 732 & 1099 & 3.98 & \\
4 & 151 & 294 & 84 & 42 & 709 & 1109 & 4.20 & \\
5 & 151 & 310 & 88 & 44 & 701 & 1096 & 4.42 & \\
\hline
\end{tabular}




\begin{tabular}{ccccccccc}
\hline 6 & 151 & 334 & 92 & 46 & 675 & 1102 & 5.10 & \\
7 & 151 & 360 & 96 & 48 & 646 & 1099 & 6.00 & \\
4.1 & 151 & 294 & 84 & 42 & 709 & 1109 & 4.20 & 0.42 \\
4.2 & 151 & 294 & 84 & 42 & 691 & 1127 & 3.99 & 0.84 \\
4.3 & 151 & 294 & 84 & 42 & 682 & 1136 & 3.99 & 1.26 \\
4.4 & 151 & 294 & 84 & 42 & 667 & 1151 & 3.70 & 1.68 \\
\hline
\end{tabular}

Methods

Compressive strength was tested according to GB/T50081-2002; Slump, setting time and air content according to GB/T50080-2002; Anti-Freeze/Thaw and Electric flux according to GB/T50082-2009. The results were shown in table 2 .

Table 2 The properties of fresh and harden concrete

\begin{tabular}{|c|c|c|c|c|c|c|c|c|c|}
\hline \multirow{2}{*}{ No. } & \multicolumn{2}{|c|}{$\begin{array}{l}\text { Slump/slump } \\
\text { flow }\end{array}$} & \multirow{2}{*}{$\begin{array}{c}\text { air } \\
\text { content } \\
\%\end{array}$} & \multirow{2}{*}{$\begin{array}{c}\text { compressive } \\
\text { strength } \\
\mathrm{MPa}\end{array}$} & \multicolumn{2}{|c|}{$\begin{array}{l}\text { 300Freeze/Thaw } \\
\text { circles }\end{array}$} & \multicolumn{2}{|c|}{$\begin{array}{l}\text { Setting time } \\
\mathrm{h}: \min \end{array}$} & \multirow{2}{*}{$\begin{array}{l}\text { Electri } \\
\text { c flux } \\
\text { C }\end{array}$} \\
\hline & $0 \mathrm{~min}$ & $60 \mathrm{~min}$ & & & $\begin{array}{l}\text { Mass } \\
\text { loss \% }\end{array}$ & $\begin{array}{l}\text { modulu } \\
\mathrm{s} \%\end{array}$ & initial & final & \\
\hline 1 & $210 / 490$ & $190 / 460$ & 2.9 & 35.6 & 5.3 & 70 & $14: 30$ & $16: 10$ & 780 \\
\hline 2 & $220 / 490$ & $210 / 490$ & 3.6 & 39.5 & 5.0 & 75 & $14: 05$ & $15: 45$ & 670 \\
\hline 3 & $220 / 510$ & $215 / 495$ & 3.4 & 42.5 & 4.5 & 79 & $13: 45$ & $15: 35$ & 640 \\
\hline 4 & $215 / 525$ & $210 / 500$ & 3.5 & 48.6 & 3.5 & 84 & $12: 38$ & $14: 40$ & 630 \\
\hline 5 & $210 / 530$ & $200 / 510$ & 2.8 & 52.6 & 3.2 & 90 & $12: 05$ & $14: 15$ & 560 \\
\hline 6 & $210 / 530$ & $205 / 520$ & 2.6 & 58.5 & 2.6 & 94 & $11: 25$ & $13: 20$ & 530 \\
\hline 7 & $200 / 510$ & $200 / 490$ & 2.4 & 64.3 & 2.0 & 98 & $10: 46$ & $12: 55$ & 450 \\
\hline 4.1 & $220 / 530$ & $215 / 510$ & 4.0 & 48.2 & 3.4 & 85 & $12: 20$ & $14: 35$ & 615 \\
\hline 4.2 & $210 / 525$ & $210 / 500$ & 4.3 & 47.6 & 3.0 & 88 & $12: 15$ & $14: 25$ & 610 \\
\hline 4.3 & $220 / 540$ & $215 / 530$ & 4.8 & 46.5 & 2.6 & 91 & $12: 12$ & $14: 10$ & 585 \\
\hline 4.4 & $215 / 525$ & $215 / 520$ & 5.5 & 44.2 & 2.2 & 93 & $11: 52$ & $13: 51$ & 570 \\
\hline
\end{tabular}

\section{Results and discussions}

The effects of water and binder ratio on air content, compressive strength and durability of concrete

The effects of water and binder ratio on air content, compressive strength and durability of concrete are shown in Fig. $1 \sim 4$. Air content in concrete is reduced with decreasing water and binder ratio. The reason may be that the smaller viscosity and more water make the bubble more easily form when the water and binder ratio is higher.

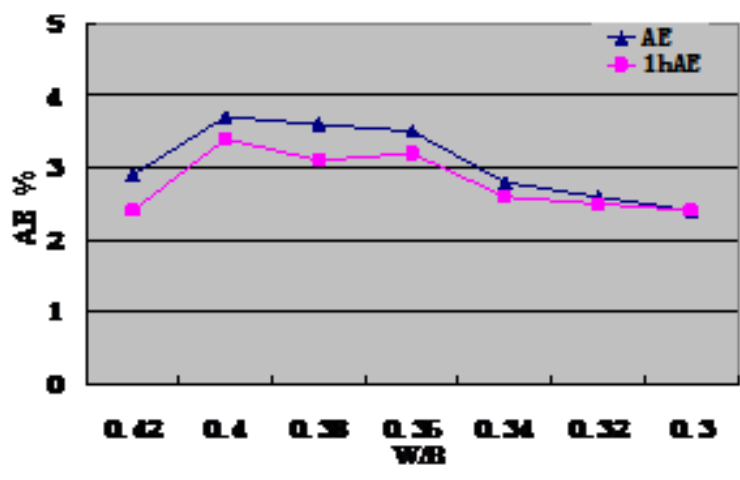

Fig.1 Effect of W/B on air content

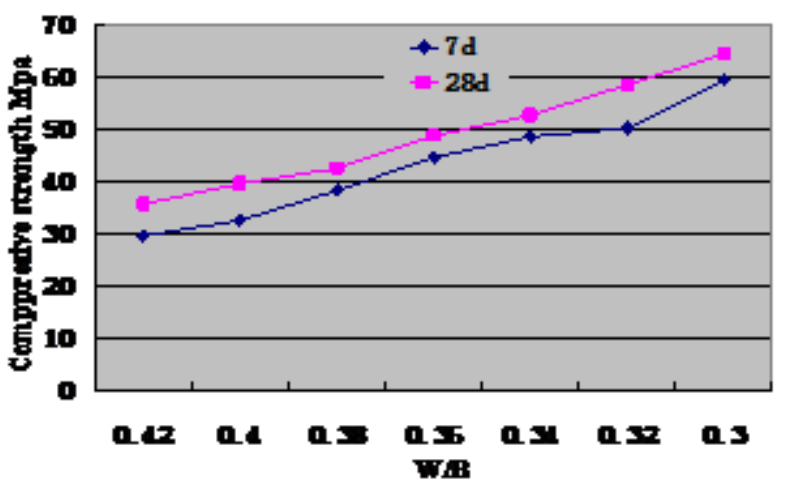

Fig.2 Effect of W/B on compressive strength 


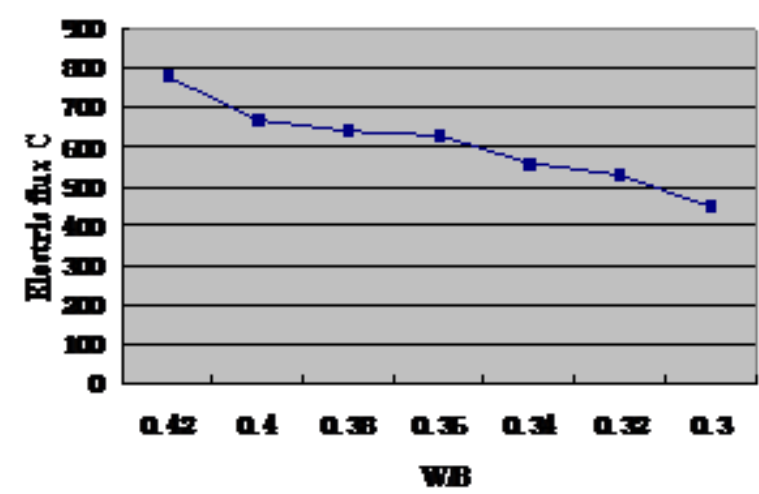

Fig.3 Effect of W/B on electric flux

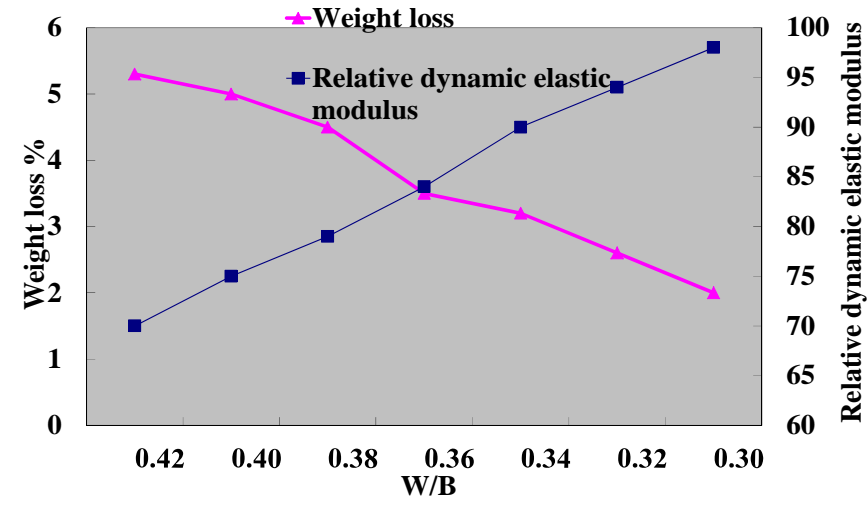

Fig.4 Effect of W/B on 300 cycles freeze/thaw

When water and binder ratio is decreased, compressive strength is increased and the electric flux reduced. The resistance of freezing and thawing is also increased. For example, mass loss is decreased from $5.3 \%$ to $2 \%$ and relative dynamic elastic modulus increased from $70 \%$ to $98 \%$ after 300 cycles. This is because lower water and binder ratio favors for increasing the compactness of concrete and lowering the porosity.

The effect of air content in concrete on workability, mechanical properties and durabilit It has been found that air entrained agent can introduce a large number of tiny and unconnected bubbles in the fresh concrete which improves the saturation degree and workability of concrete mixture. It also can alleviate the expansion pressure and osmotic pressure caused by freeze-thaw damage. As a result, the durability of concrete is improved.

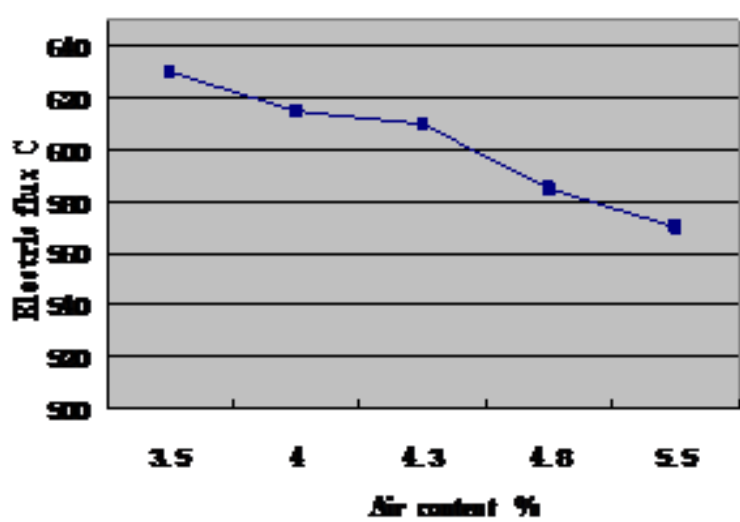

Fig.5 Effect of air content on electric flux
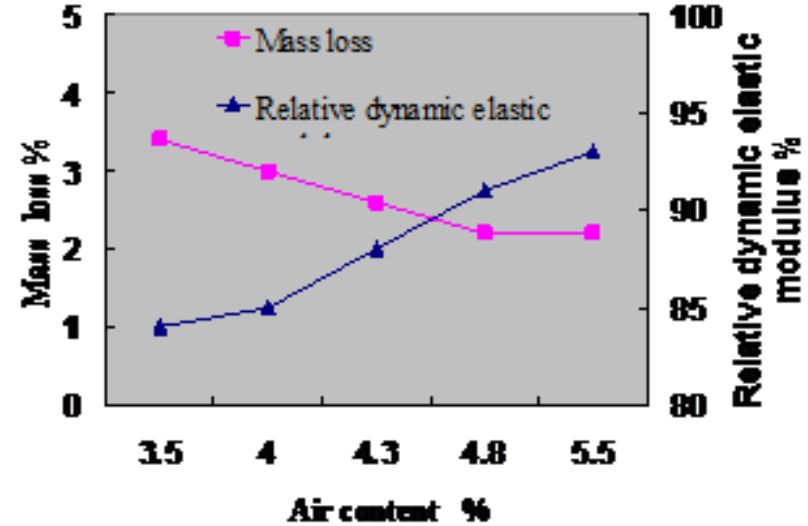

Fig. 6 Effect of air content on 300 cycles freeze/thaw

When water amount and slump is kept almost the same, air entrained agent reduces the dosage of superplasticizer. The reason is that air entrained agent increases the content of tiny bubbles which can improve the package of aggregate and the fluidity of fresh concrete. With the increase in air content, compressive strength of concrete is decreased, but the change is not very obvious. The electric flux of concrete is, however, reduced from $615 \mathrm{C}$ to $517 \mathrm{C}$. Mass loss is also reduced from $3.4 \%$ to $2.2 \%$, and relative dynamic elastic modulus increased from $85 \%$ to $93 \%$ after 300 freeze-thaw cycles.

\section{The pore structure analysis}

Air content of concrete is not sole parameter which affects the frost resistance of concrete, and the number, distribution and size of the bubble are also some key factors. Even if air content is the same, the size and number of the bubble is different, and bubble spacing coefficient varies more widely. As a result, concrete has different frost resistance.

The frost-resistant sample with $100 \times 100 \times 400 \mathrm{~mm}$ was cut into $100 \times 100 \times 10 \mathrm{~mm}$ slice. After the slice is successively ground, polished, cleaned and coloring treatment, the content, specific 
surface area and porosity, spacing coefficient and average chord length of bubbles in the surface of the slice were measured by RapidAir 457 hardened concrete porosity analyzer, as shown in figure 7 and table 3 .
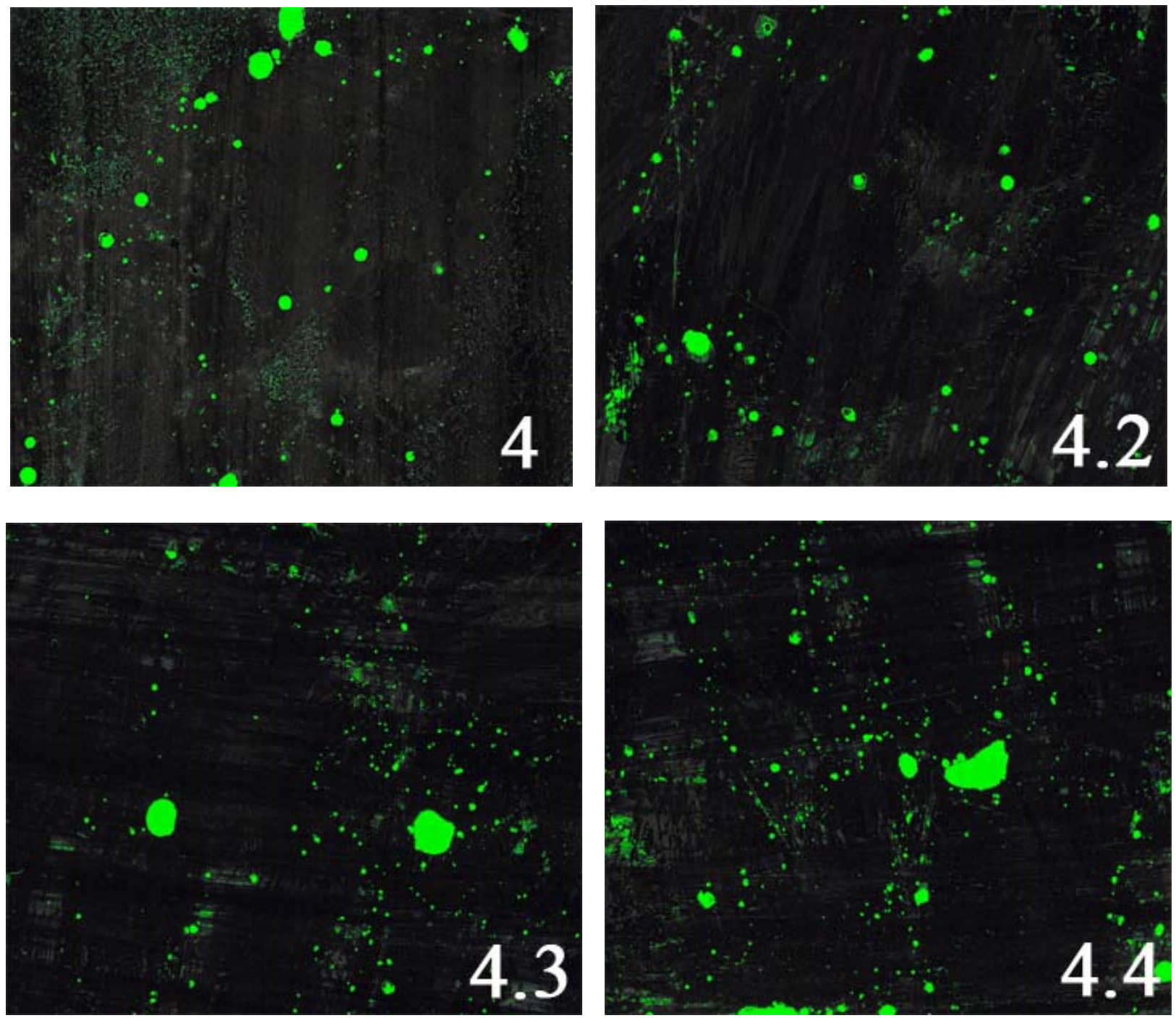

Fig.7 Bubble scatter of hardened concrete

Table 3 Bubble parameters of hardened concrete

\begin{tabular}{cccccc}
\hline No. & $\begin{array}{c}\text { Air content } \\
\%\end{array}$ & $\begin{array}{c}\text { specific area } \\
\left(\mathrm{mm}^{2} \cdot \mathrm{m}^{-1}\right)\end{array}$ & $\begin{array}{c}\text { spacing coefficient } \\
(\mathrm{mm})\end{array}$ & $\begin{array}{c}\text { frequency } \\
\left(\mathrm{mm}^{-1}\right)\end{array}$ & $\begin{array}{c}\text { average chord } \\
\text { length }(\mathrm{mm})\end{array}$ \\
4 & 3.5 & 38.77 & 0.302 & 0.131 & 0.206 \\
4.2 & 4.3 & 55.42 & 0.121 & 0.352 & 0.072 \\
4.3 & 4.8 & 58.99 & 0.080 & 0.810 & 0.068 \\
4.4 & 5.5 & 69.44 & 0.056 & 1.305 & 0.058
\end{tabular}

With the increase in air content, specific surface area shows a trend of increase. The spacing coefficient and average chord length is decreased. The results indicate that the frost resistance of concrete will be enhanced. 


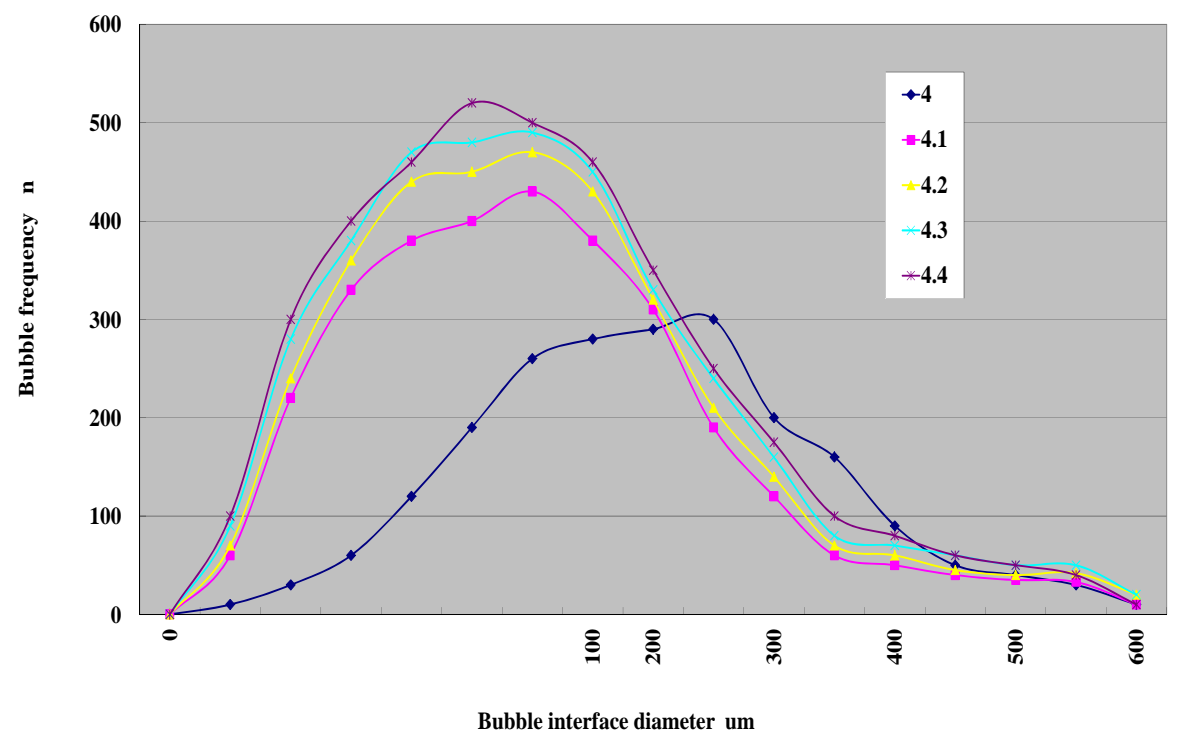

Fig.8 Relationship of bubble size and bubble frequency

The relation of bubble size with frequency distribution is given in Fig. 8. With the increase in the amount of air entrained agent, the number of small bubbles, especially less than $100 \mu \mathrm{m}$, in the amples. The sample without air entrained agent has, however, more bubble greater than $100 \mu \mathrm{m}$. This indicates that air entrained agent improves the stability of less than $100 \mu \mathrm{m}$ bubbles.

\section{Summary}

The air content of concrete is related to water and binder ratio. The lower water and cement ratio is, the less air content is. (2) The relationship of water and binder ratio with compressive strength, the electric flux and anti-frost index almost show linear changes. (3) Air content of concrete has a great influence on the workability, and appropriate air content can improve the workability and durability of concrete. (4) The quality of air bubbles is the most fundamental factor affecting the durability of concrete. The more the number of less than 100 um bubbles is, the better the durability of concrete is.

\section{References}

[1] Provisional rules of durability design of railway reinforced concrete structure.

[2] The durability design of concrete structure and construction guidelines (CCES 01-2001). China building industry press.

[3] Yaqing Jiang, The engineering application of polycarboxylate air entrained agent Journal of southeast university Vol. 36, No. 4

[4] Weibao Liu,Determination of bubble parameters of RCC by planar scanning image recognition method. Meeting on the chemistry and application technology of cement and concrete, 2007

[5] Jingjie Yang,Study on the relationship between frost resistance of air-entraining concrete and the bubble structure. Soil Engineering and Foundation Vol. 19 No. 2 